\title{
AS CONSTANTES MUDANÇAS NOS CONTEXTOS DA FORMAÇÃO DE PROFESSORES NO BRASIL
}

Keila Ferreira Pavaneli

Marcelo Máximo Purificação

Universidade Estadual do Mato Grosso do Sul - UEMS

Universidade Estadual do Mato Grosso do Sul - UEMS

Resumo: Nos últimos anos, as políticas voltadas para a formação de professores passaram a ser foco de interesse de governantes, pesquisadores e profissionais da educação, o que vem gerando uma reestruturação no que se refere à formação dos professores brasileiros, independentemente do grau de ensino a lecionar. Quando se fala em formação de professores em um país como o Brasil, deve-se primeiro caracterizar o contexto do país, que no caso é um país continental, com uma cultura ampla e diversa, o que desafia nossos professores exigindo cada vez mais desses profissionais, por isso a importância de forma-los adequadamente. Na medida em que as políticas educacionais estão vinculadas a uma boa e contínua formação de professores, a educação em geral será mais benéfica. Isso se deve a uma variedade de competências, técnicas, ferramentas e metodologias que nos permitem refletir sobre uma visão integrada entre alunos e professores.

Palavras-chave: Desenvolvimento. Educação. Formação de professores.

\section{CONSTANT CHANGES IN THE CONTEXTS OF TEACHER TRAINING IN BRAZIL}

\begin{abstract}
In recent years, policies aimed at teacher training have become the focus of interest for government officials, researchers and education professionals, which has been generating a restructuring with regard to the training of Brazilian teachers, regardless of the level of education to be taught. When it comes to teacher training in a country like Brazil, we must first characterize the context of the country, which in this case is a continental country, with a wide and diverse culture, which challenges our teachers by demanding more and more of these professionals, so the importance of properly training them. To the extent that educational policies are linked to good and continuous teacher training, education in general will be more beneficial. This is due to a variety of skills, techniques, tools and methodologies that allow us to reflect on an integrated vision between students and teachers.
\end{abstract}

Key words: Development. Education. Teacher training.

Como citar o artigo: PAVANELI, Keila Ferreira. PURIFICAÇÃO, Marcelo Máximo. As constantes mudanças nos contextos da formação de professores no brasil. Revista Científica Novas Configurações-Diálogos Plurais, v. 2 n. 1, 2021

\section{INTRODUÇÃO}

A importância fundamental da formação de professores em todos os níveis educacionais, tanto iniciais quanto continuadas, e seu status como elemento essencial para o sucesso do sistema educacional, é um fato aceito

Fonte de financiamento: Nenhum

Conflito de interesse: Os autores declaram não haver Nenhum conflito de interesse.

E-mail do autor-correspondência: keila.pavaneli@etec.sp.gov.br

Data de recebido: $12 / 09 / 2020$

Data de aprovado: $16 / 12 / 2020$

Editora: Elisângela Maura Catarino. 
como totalmente verdadeiro pelos especialistas e pela comunidade educacional. A renovação pedagógica, inovação e pesquisa fazem parte da função de ensino para favorecer a melhoria contínua dos processos de ensino e aprendizagem em diferentes níveis e estágios educacionais (GATTI, 2016).

A sociedade está em contínua transformação. A maneira como os alunos aprendem mudou, suas necessidades e circunstâncias não são as mesmas de dez anos atrás, e a organização da resposta educacional não será a mesma em vinte (ALVES, 2015). Nessa linha de pensamento PURIFICAÇÃO et. al (2020, p.197) salientam que "os processos pedagógicos que se desenvolvem nos espaços escolares, ou em função deles, são fundamentais para se pensar, fundamentar e estruturar a dimensão da educação como processo de formação humana".

Devido a essa alta importância dos docentes para o país estamos constantemente nos perguntando: A formação dos professores atualmente ensinados nas universidades corresponde à realidade que os futuros professores encontrarão na sala de aula? As ferramentas são dadas para enfrentar a educação no século XXI? Damos importância suficiente à formação contínua de professores? Portanto não há dúvidas, o maior objetivo é assegurar que os professores estejam em constante formação e renovação pedagógica.

Uma das competências gerais do cidadão do século XXI é a de aprendizado ao longo da vida; em um mundo em constante mudança, não pode ser de outra maneira. Agora, se essa competência é parte essencial da adaptação ao mundo em que vivemos, a responsabilidade de desenvolvê-la se multiplica quando se fala sobre o grupo de pessoas que ensinam e educam crianças e jovens, pois estão lançando as bases para seu pleno desenvolvimento, para que possam ser cidadãos comprometidos com a melhoria da sociedade, da vida ou do planeta (CANDAU, 2017).

A qualificação do professor deve ser adquirida a partir da formação inicial, que é objetivamente improvável. Dito isto, já se começa com uma lacuna entre formação recebida e as habilidades realmente necessárias no desempenho de uma das profissões mais complexas que existem. Pode-se acrescentar que o desenvolvimento que está sendo dado à educação graças à pesquisa, à neurociência e às experiências bemsucedidas de qualquer parte do mundo está hoje muito próximo (GATTI e BARRETO, 2015).

Isso abre portas e janelas para uma carreira que, embora às vezes pareça desestimulante, ainda é um desafio necessário, para que a tarefa de ensino seja acompanhada por melhores estratégias, técnicas e modelos que o ajudem a alcançar seus fins. Devido a essa importância o objetivo do trabalho foi realizar uma análise sobre as mudanças ocorridas nos últimos anos no que tange a formação dos professores no Brasil.

\section{FORMAÇÃO DE PROFESSORES NO BRASIL.}

\subsection{Contexto histórico}

Nos penúltimos decênios do século XX ocorreu um marco histórico para a pedagogia no Brasil, quando teóricos engajados na discussão sobre o rumo da educação e da didática trataram da problematização do esvaziamento teórico político da didática nos cursos de formação de professores e da superação da didática instrumental rumo à construção de uma didática fundamental de acordo com Candau (2015).

Segundo Freitas (2012, p.138), 


\begin{abstract}
Para traçar uma visão panorâmica da formação de professores em nosso país, tomo como ponto de partida as análises que vêm sendo feita pelos educadores (Freitas, L.C., 2000; Freitas, H., 1999; Kuenzer, 1998; Valle, 1999, 2000; entre outros) e por suas entidades organizativas - ANFOPE, FORUMDIR, ANPED, ANPAE, CEDES, Fórum Nacional em Defesa da Formação de Professores, CNTE, entre outras - no sentido de identificar os (des)caminhos das políticas de formação de professores nos últimos dez anos, buscando nesta história identificar os elementos de superação das condições atuais em que se encontra a educação e em particular a formação de professores, campos assolados pelas determinações dos organismos internacionais que impõem aos diferentes países seus fins e objetivos, tornando-os subordinados às orientações políticas neoliberais e mais bem adequados às transformações no campo da reestruturação produtiva em curso.
\end{abstract}

Entre 1980 e 1990, foram tomadas medidas significativas em relação à universalização de acesso ao ensino fundamental obrigatório, bem como a expansão do Educação secundária (GOLDEMBERG, 2013).

Com a promulgação da Lei 9394, de Diretrizes e Bases da Educação Nacional (LDB), em 1996, iniciouse uma nova etapa de reformas, com a intenção de consolidar e aprofundar a linha anterior. Nesse contexto, políticas de apoio foram propostas para sistemas estaduais e municipais para melhorar a qualidade da educação. Quão principal aspecto, é necessário mencionar a elaboração de um conjunto de referências pedagógicos denominados Parâmetros Curriculares Nacionais, destinados a oito séries de ensino fundamental (BRASIL, 1996).

Nesse contexto, foi necessário vincular a melhoria da qualidade da educação com a da qualidade da formação de professores. Isso envolveu uma revisão aprofundada dos diferentes aspectos que influenciam a formação inicial de professores: organização institucional, definição e estruturação de conteúdo, desenvolvimento de competências do professor, etc. No Brasil, a produção teórica e prática da área educacional do movimento de educadores, desde o final dos anos 70, com o processo de democratização da sociedade, fez novas exigências para a melhoria da escola básica e para o treinamento dos professores (FREITAS, 2012).

Associação Nacional de Formação de Profissionais da Educação (ANFOPE) - é uma das entidades que contribuiu para essa discussão coletiva reafirmando uma concepção sócio histórica do educador em oposição ao caráter técnico e contencioso que vinha caracterizando muitas políticas de formação de professores, até então (AGUIAR, 2017).

Essa concepção sócio histórica do educador, definida pelo movimento nacional de educadores e defendidos pelo ANFOPE é um conceito de ampla formação profissional que inclui total domínio e compreensão da realidade de seu tempo, com consciência crítica que lhe permite interferir e transformar as condições da escola, educação e sociedade.

De acordo com o documento da Comissão Nacional para a Formação de Profissionais da Educação CONARCFE de 1989 (comissão da qual a ANFOPE):

O educador como profissional de ensino (...), tem o ensino como base de sua identidade profissional, domina o conhecimento específico de sua área, articulado a pedagógico, numa perspectiva da totalidade do conhecimento socialmente produzido que permite perceber as relações entre atividades educacionais e a totalidade das relações sociais, econômicas, políticas e culturais nas quais o processo ocorre 
educacional, podendo atuar como agente transformador da realidade em que está inserido. (FREITAS, 1999, s/p).

Na trajetória dos educadores, observa-se sua luta pela qualificação da formação, pela definição de uma política nacional global contínua e integrada para a formação de profissionais em educação e pela valorização da profissão docente. Essa avaliação deve contemplar, no marco das políticas educacionais e nas condições de equidade: sólida formação inicial no campo da educação e condições de trabalho, salário e carreira decentes (FREITAS, 2012).

Além disso, e especialmente, os princípios que orientam a formação inicial e contínua de educadores que fundaram a luta dos movimentos da ANFOPE, representam como um direito de professores e dever do Estado e dos demais mantenedores de escolas de treinamento que, devem estabelecer diretrizes para esse treinamento contínuo, a fim de atender a necessidades de professores, escolas e alunos, contribuindo para o escopo de resultados positivos de aprendizagem que a sociedade exige (LIBÂNEO, 2015).

\subsection{Contexto legal}

Para falar em mudanças no contexto de formação dos docentes no Brasil é primordial atentar-se a algumas Leis e Decretos entre eles, de acordo com seus respectivos anos de publicação:

- $\quad$ Lei no 9.394, de 20 de dezembro de 1996 (LDB) - Diretrizes e bases da educação nacional;

- $\quad$ Resolução CNE/CEB nº 3, de 26 de junho de 1998 - Diretrizes Curriculares Nacionais para o Ensino Médio;

- $\quad$ Resolução CNE/CP n ${ }^{\circ}$ 1, de 30 de setembro de 1999 - Institutos Superiores de Educação;

- $\quad$ Lei n $n^{\circ}$ 10.172, de 9 de janeiro de 2001 - Plano Nacional de Educação (PNE 2001- 2010);

- $\quad$ Resolução CNE/CP n ${ }^{\circ}$ 1, de 18 de fevereiro de 2002 - Diretrizes Curriculares Nacionais para a Formação de Professores da Educação Básica, em nível superior, curso de Licenciatura, de graduação plena; curso de Pedagogia;

- Resolução CNE/CP n ${ }^{\circ}$ 1, de 15 de maio de 2006 - Diretrizes Curriculares Nacionais para o

- $\quad$ Lei no 9.424 de 24 de dezembro de 1996 - Fundo de Manutenção e Desenvolvimento do Ensino Fundamental e de Valorização do Magistério (FUNDEB);

- $\quad$ Lei $n^{\circ} 11.738$, de 16 de julho de 2008 - Piso salarial profissional nacional para os profissionais do magistério público da educação básica;

Lei n ${ }^{\circ} 11.892$, de 29 de dezembro de 2008 - Rede Federal de Educação Profissional, Científica e Tecnológica, cria os Institutos Federais de Educação, Ciência e Tecnologia;

- Decreto n ${ }^{\circ}$ 6.755, de 29 de janeiro de 2009 - Política Nacional de Formação de Profissionais do Magistério da Educação Básica;

- $\quad$ Portaria Normativa MEC no 9, de 30 de junho de 2009 - Plano Nacional de Formação dos Professores da Educação Básica no âmbito do Ministério da Educação; 
- $\quad$ Portaria CAPES n ${ }^{\circ} 122$, de 16 de setembro de 2009 - Programa Institucional de Bolsa de Iniciação à Docência, no âmbito da CAPES (PIBID);

- $\quad$ Portaria do MEC no 1.087, de 10 de agosto de 2011 - Comitê Gestor da Política Nacional de Formação Inicial e Continuada de Profissionais da Educação Básica;

- $\quad$ Portaria MEC n $n^{\circ} 1.328$, de 23 de setembro de 2011 - Rede Nacional de Formação Continuada dos Profissionais do Magistério da Educação Básica Pública;

- $\quad$ Lei $n^{\circ} 13.005$, de 25 de junho de 2014 - Aprova o Plano Nacional de Educação -PNE e dá outras providências (PNE 2014-2024); Educação Básica.

- $\quad$ Decreto no 8.752, de 9 de maio de 2016 - Política Nacional de Formação dos Profissionais da

- $\quad$ Fórum das Licenciaturas;

- $\quad$ Conferências Nacionais de Educação (CONAEs) - 2010 e 2014;

Básica.

- $\quad$ Fóruns Estaduais e Distrital Permanentes de Apoio à Formação dos Profissionais da Educação

É preciso citar que no ano 2019, quatro leis que modificaram a LDB, entre elas:

- $\quad$ Lei $n^{\circ} 13.796$, de 3 de janeiro de 2019

- $\quad$ Lei $\mathrm{n}^{\mathbf{0}} 13.803$, de 10 de janeiro de 2019

- $\quad$ Lei $\mathrm{n}^{\circ} 13.826$, de 13 de maio de 2019

- $\quad$ Lei $n^{\circ} 13.868$, de 3 de setembro de 2019

De acordo com o Plano Nacional de Educação (PNE), os cursos de treinamento devem obedecer, em qualquer um de seus níveis e modalidades, aos seguintes princípios:

- $\quad$ sólida formação teórica nos conteúdos específicos que devem ser ministrados em educação básica, bem como especificamente pedagógicas;

- Treinamento cultural extensivo;

- $\quad$ Atividade de ensino como núcleo de treinamento; prática pedagógica;

Contato com a realidade escolar desde o início até o final do curso, integrando teoria com

- $\quad$ Pesquisa como princípio de treinamento;

- Domínio de novas tecnologias de comunicação e informação, e capacidade de integrá-los à prática de ensino;

- $\quad$ Análise das questões atuais da sociedade, cultura e economia;

- Inclusão de questões relacionadas à educação de alunos com necessidades especiais e questões étnicas e de gênero programas de formação;

Trabalho coletivo interdisciplinar;

- $\quad$ Experiência de formas democráticas de gestão do ensino durante o curso;

- Desenvolvimento do compromisso social e político da profissão docente e

- Conhecimento e aplicação das diretrizes curriculares nacionais dos níveis e modalidades de educação básica. 
Institutos superiores de educação se reportam ao Ministério da Educação Superior (SESU) do Ministério da Educação e Cultura, que corresponde à análise os processos que desenvolvem e solicitam a aprovação do Conselho Nacional de Educação (BRASIL, 2020).

É garantido o treinamento contínuo de profissionais da educação pública secretarias estaduais e municipais de educação, cujas ações incluem a coordenar, financiar e sustentar programas como ações permanente, e a busca de alianças com universidades e instituições de ensino superior. O parente dos professores que trabalham na esfera privada é responsabilidade das diferentes instituições

\begin{abstract}
Melhorar radicalmente a formação de professores requer uma série de políticas articuladas, pois o desafio não é simples: apesar de termos boas experiências no Brasil, a maioria dos cursos negligenciam a articulação da teoria com a prática, pouco tratam dos conteúdos que os futuros docentes deverão ensinar e estão descolados da realidade das escolas. Com as novas DCN, há uma clara indução para que esses desafios sejam enfrentados", diz Priscila Cruz, presidente-executiva do Todos Pela Educação (BRASIL, $2020, \mathrm{a}, \mathrm{s} / \mathrm{p})$.
\end{abstract}

Mudanças de acordo com os anos:

2016: - Publicação do livro "Formação de Professores no Brasil - Diagnóstico, agenda de políticas e estratégias para a mudança", coordenado pelo Professor Fernando Abrucio, da Fundação Getúlio Vargas de São Paulo (FGV-SP). O estudo traz um panorama geral sobre o tema e elenca alguns caminhos a serem seguidos, dentre eles a necessidade de mudanças na regulação da formação inicial.

2017: - Coordenação de um grupo de especialistas em formação de professores, para estruturar um diagnóstico claro dos principais entraves e propor soluções concretas de políticas públicas. Foi o início da iniciativa "Profissão Professor", que posteriormente virou um esforço independente e que hoje se chama "Movimento Profissão Docente".

Em parceria com o CENPEC, produção e disseminação da pesquisa "Consensos e dissensos em torno da definição de Referenciais de Atuação Docente”, para melhor qualificar o debate sobre os principais argumentos a favor e contra a definição de um marco referencial docente que estabeleça os conhecimentos e competências profissionais dos professores.

Em parceria com a FGV-SP, produção e disseminação de outras duas pesquisas que também se aprofundaram em experiências nacionais e internacionais de marcos referenciais: "Métodos Inovadores de Ensino: As Experiências Nacionais de Referenciais de Atuação Docente" e "Métodos Inovadores de Ensino: As Experiências Internacionais de Referenciais de Atuação Docente".

- Organização do evento "Seminário Técnico - Referenciais da Atuação Docente", com a presença de duas das principais referências internacionais sobre o tema: Cristián Cox, do Chile e Margery Evans, da Austrália. Foram mais de 80 especialistas brasileiros participando e debatendo sobre a importância dessa agenda para uma transformação sistêmica da formação e carreira de professores.

2018: - No âmbito da iniciativa Educação Já! coordenação de um grupo de trabalho para construir propostas de políticas públicas nacionais para a valorização e profissionalização docente, que incluiu recomendações para a melhoria da formação inicial de professores. Dentre as propostas, estavam a definição de um Marco Referencial Docente nacional, para nortear as políticas docentes, e a revisão das DCN para os cursos de Pedagogia e demais Licenciaturas. Essas propostas foram apresentadas para representantes do Governo Federal, do CNE, do Congresso Nacional e de gestões estaduais e municipais.

Apresentação à então gestão do Ministério da Educação de subsídios técnicos para o esforço de elaboração da Base Nacional Comum para Formação de Professores da Educação Básica, documento apresentado em dezembro de 2018 que deu embasamento à revisão das DCN promovida pelo CNE. 


\begin{abstract}
Condução, em conjunto com o Itaú Social e o Ibope, de uma pesquisa quantitativa de opinião com professores de todo o Brasil, buscando entender a visão dos docentes brasileiros sobre diversos tópicos da Educação.
\end{abstract}

- $\quad$ Apoio ao fortalecimento do Movimento Profissão Docente, que tem contribuído substantivamente para o avanço de importantes medidas a nível federal e estadual, dentre elas as próprias DCN recém-aprovadas.

2019: - Apresentação das propostas sobre políticas docentes produzidas no Educação Já! Para a nova gestão do Ministério da Educação, para deputados e senadores eleitos e para secretários de Educação de Estados e Municípios.

- Construção de um acordo de cooperação técnica com o Conselho Nacional de Educação para, junto com o Movimento Profissão Docente, fornece apoio técnico para as discussões a respeito de políticas docentes.

Produção de estudos sobre a formação inicial de professores no Brasil, mostrando a expressiva elevação de cursos na modalidade a distância e de baixa qualidade ("Formação Inicial de Professores no Brasil" e "A Expansão do ProUni EAD na Formação Inicial Docente").

- $\quad$ Participação na audiência pública promovida pelo CNE a respeito das novas DCN. Nesta ocasião, reforçamos o apoio ao trabalho realizado pelo Conselho e apontando sugestões de melhorias ao documento que foi colocado em consulta pública.

- $\quad$ Também em parceria com o Movimento Profissão Docente, envio ao CNE de um documento técnico com sugestões de melhorias no parecer em discussão sobre a temática (BRASIL, 2020, b).

É por isso que a formação de professores é importante, pela mesma razão que a formação permanente de médicos, advogados ou engenheiros é importante. Ninguém gostaria de saber que seu médico continuou a usar os recursos e prescrever medicamentos de 50 anos atrás, quando a adequação de novos tratamentos ou medicamentos foi cientificamente comprovada. Da mesma forma, ninguém gostaria de experimentar um medicamento em seus filhos que não tivesse sido contrastado e aprovado pelos órgãos competentes (AGUIAR, 2017).

No entanto, é comum ver como as propostas são testadas nas salas de aula que, longe de serem testadas quanto à funcionalidade, eficácia ou transferibilidade, são experimentadas com alegria e compartilhadas nas redes sociais para que outras pessoas possam colocar em prática. Precisa-se de uma formação de professores de qualidade, mas é claro que a atual tem demonstrado há anos que não gera uma mudança substancial e generalizada nas salas de aula. Não há relação positiva entre os investimentos de tempo, esforço e dinheiro e a inovação observada nas salas de aula (MARQUES, 2017).

A atualização é essencial e temos a obrigação de torná-la eficaz.

\title{
CONCLUSÃO
}

Melhorar a qualidade do processo de ensino-aprendizagem requer influenciar aspectos como professores, programas, estudantes, infraestrutura, avaliação, entre outros. Mudanças na formação de professores exigem direcionar a atividade de ensino para o desenvolvimento de capacidades, habilidades, atitudes e valores 
que possibilitem o treinamento por competências para se adaptar às mudanças sociais, econômicas e tecnológicas e transformar nossa realidade.

Confrontado com os métodos tradicionais de transmissão de conhecimento e ensino focados no papel do ensino, e não na aprendizagem ou auto regulação, o processo de aprendizagem está no centro da mudança metodológica. O modelo de ensino-aprendizagem baseado em competências destaca que o importante não é o que o professor sabe ou faz, mas o que os alunos aprendem e como aprendem.

Tudo isso implica o desafio das faculdades de educação de uma atualização científica e técnica contínua de seus conhecimentos e da aquisição de novas competências profissionais como professores e para futuros professores. Daí a necessidade da formação de professores surgir de um processo de desenvolvimento profissional contínuo e integrado, que deve continuar ao longo da vida, sendo construído por uma formação sequencial.

Por fim, enfatizar a responsabilidade que recai sobre as universidades de educação e formação de professores, como referenciais na criação de conhecimento científico, pedagógico e didático, para capacitar estudantes universitários e, principalmente, para a transposição didática, desde a orientação e a qualidade desse treinamento profissional afetará todos os outros estágios educacionais.

\section{REFERÊNCIAS}

AGUIAR, M.A. A formação do profissional da educação no contexto da reforma educacional brasileira. In: FERREIRA, N.S.C. (Org.). Supervisão educacional para uma escola de qualidade. São Paulo:Cortez, 2017.

ALVES, N. (Org.). Formação de professores: pensar e fazer. São Paulo: Cortez, 2015.

BUSSMANN, A.C. Formação Inicial e Continuada de Professores. Palestra ministrada na Secretaria Estadual de Educação/RS/Brasil. agosto/2016.

BRASIL. Legislação Informatizada - LEI no 9.394, de 20 de dezembro de 1996. Disponível em: https://www2.camara.leg.br/legin/fed/lei/1996/lei-9394-20-dezembro- 1996-362578-publicacaooriginal-1pl.html. Acesso em maio de 2020. (A)

BRASIL. Formação inicial de professores: Mudanças Aprovadas pelo CNE

podem ser início de grande transformação. $\quad$ Disponível

em:

https://www.todospelaeducacao.org.br/conteudo/Formacao-inicial-de-professores-mudancas-aprovadas-peloCNE-podem-ser-inicio-de-grande-transformacao. . . . .

CANDAU, V.M.F. Didática: questões contemporâneas. 32ªed. Rio de Janeiro: Vozes, 2015.

CANDAU, V.M.F. (Org.). Novos rumos da licenciatura.12ª ed. Brasília, DF: INEP/PUC-RJ, 2017.

FREITAS, H.C.L. A Reforma do Ensino Superior no campo da formação dos profissionais da educação básica: as políticas educacionais e o movimento dos educadores. In: Educação e Sociedade - Revista Quadrimestral de Ciência da Educação/Centro de Estudos Educação e Sociedade, nº 68, 1999.

FREITAS, H.C.L Formação de professores no Brasil: 10 anos de embate entre projetos de formação. Educ. Soc., Campinas, vol. 23, n. 80, setembro/2012, p. 136- 167

GATTI, B.A. Formação de professores no Brasil: características e problemas. Educ. Soc. 2016, vol.31, n.113, 
pp.1355-1379.

GATTI, B.A.; BARRETO, E.S.S. Professores: aspectos de sua profissionalização, formação e valorização social. Brasília, DF: UNESCO, 2015. (Relatório de pesquisa).

GOLDEMBERG, José. O repensar da educação no Brasil. Estud. av., São Paulo, v. 7, n. 18, p. 65-137, ago. 2013.

LIBÂNEO, JC. Organização e gestão da escola - teoria e prática. Goiânia: Alternativa, 2015.

MARQUES, M.O. A reconstrução dos cursos de formação do profissional da educação. Em Aberto, Brasília, DF, n. 54, p. 7-18, 2017.

PURIFICAÇÃo, Marcelo Máximo; CATARINO, Elisângela Maura; TEIXEIRA, Maria Filomena Rodrigues; SANTANA, Lousana de Jesus; ABDALLA, Cláudia de Souza; ALVES, Angélica Ferreira (2020). Curriculum and Identity its Impacts on the School Context in Goiás: Points and Counterpoints. Am. In. Mult. J., Jul to Oct. (9) 5, 196-204

Informações sobre os autores:

KFP: Aluna do Programa de Pós-Graduação em Educação pela Universidade Estadual de Mato Grosso do Sul - UEMS - Brasil. E-mail: keila.pavaneli@etec.sp.gov.br

MMP: Pós-Doutor em Educação pela Universidade de Coimbra-Portugal. Doutor em Ciências da Religião - PUC -Goiás e Doutor em Ensino pela UNIVATES. Professor Permanente do Programa de Pós-graduação em Educação da Universidade Estadual do Mato Grosso do Sul - UEMS.

Contribuições dos autores: (KFP-MMP) conceitualização, captação de recursos, supervisão, redação 